\title{
SWAKELOLA MANAJEMEN BURUH
}

\author{
Fatwa Zuhaena
}

\section{Universitas Wijaya Kusuma}

\author{
Tri Esti Masita
}

\section{Universitas Wijaya Kusuma}

\author{
Arinastuti
}

\section{Universitas Wijaya Kusuma}

\section{Abstract}

This paper proposed the idea to remove the wage system based on stipulated in Law No. 13 of 2003 on Employment, and build a new system based on the Employment Act with a new revenue-sharing and self-management.

The idea is implemented by means of disseminating discourse abolition of the wage system and replace it with a system of profit-sharing and self-managed workers' sector alliances. And workers alliance solidarity and create strategis for action both mass action and structural measures. Intended structural action is to conduct a judicial review of Law No. 13 of 2003 concerning anything pertaining to wages in the employment relationship, to be blasted in Article 28D (2) of the 1945 Constitution. Then prepare an academic paper about the result and the self-management system inLaw the new Labor Law to be submitted to Parliament and Kemenarkertans. Then the discussion is mengkawal the text has to be approved and implemented.

Later sharing system and self-management will be a new system in Employmet Act new. Later there will be no more that workers took to the streets, which is considered to impede the course of the national economy. No more demands for wage increases, minimum wage, working hours, outsouring, freedom of association, and other demands. Because of this new system makes workers obtain kedaulatannya, while industrialist also not left out of the corporate world. With this new system, then sociaty will succesfully obtain justice, well-being and economic independence. Keywords: self-management, profit sharing, wage laborers. 


\section{PENDAHULUAN}

Gejolak pekerja yang terjadi di Indonesia tak kunjung usai. Masalah-masalah ketenagakerjaan terus menerus muncul. Dalam data yang dikumpulkan menurut Tempo, terjadi kenaikan yang signifikan terhadap protes kebijakan ketenagakerjaan nasional. Tahun 2010 di Istana negara sekitar 75.000 pekerja turun ke jalan menuntut konsistensi jaminan tenaga kerja ${ }^{1}$. Tahun 2011 ribuan pekerja yang tergabung dalam 14 serikat pekerja menuntut dihapuskannya outsourcing dan konsistensi pelaksanaan kebebasan berserikat ${ }^{2}$. Hingga pada 2012 sejumlah 100.000 pekerja turun ke jalan mendatangi Istana Negara, Gelora Bung Karno, dan Bundaran HI menuntut kesejahteraan pekerja ${ }^{3}$.

Namun berbagai aksi tersebut ternyata belum menyentuh akar dari masalah ketenagakerjaan, yaitu keadilan. Penulis meyakini dengan alasan yang ilmiah bahwa sistem upah yang ada tidak membawa keadilan pada pekerja, terlebih pada kesejahteraan nasional.

Tujuan dari gagasan ini ialah :

1. Mewujudkan ketenagakerjaan yang berkeadilan

2. Memberi wacana kepada khalayak masyarakat pada umumnya dan civitas akademika pada khususnya mengenai Penerapan Sistem Bagi Hasil (Profit Sharing) Dan Swa Kelola (Workers Self Management) Dalam Hubungan Kerja Secara Nasional Sebagai Solusi Terhadap Krisis Sistem Uoah Di Indonesia.

Manfaat dari gagasan ini adalah :

1. Sebagai bacaan evaluasi, refleksi dan solusi atas permasalahan ketenagakerjaan.

2. Memberlakukan sistem yang lebih berkeadilan dan demokratis dengan bagi hasil dan swakelola.

Dari penjabaran diatas, suatu permaslahan yang hendak diteliti yaitu "Bagaimanakah Metode yang Tepat untuk Sistem Pengupahan Buruh ?"

\section{TINJAUAN PUSTAKA}

A. Upah 
Sistem upah yang berlaku di Indonesia diatur dalam Pasal 1 angka 30 UndangUndang Nomor 13 tahun 2003 tentang Ketenagakerjaan. Pasal tersebut menyatakan bahwa upah adalah hak pekerja/buruh yang diterima dan dinyatakan dalam bentuk uang sebagai imbalan dari pengusaha atau pemberi kerja kepada pekerja/buruh yang ditetapkan dan dibayarkan menurut suatu perjanjian kerja, kesepakatan, atau peraturan perundang undangan, termasuk tunjangan bagi pekerja/buruh dan keluarganya atas suatu pekerjaan dan/atau jasa yang telah atau akan dilakukan. Selain itu hak pekerja juga diatur dalam Undang-Undang Dasar Negara Replubik Indonesia Tahun 1945 (UUD 1945) dalam pasal 28B ayat (2) yang menyatakan bahwa setiap orang berhak untuk bekerja serta mendapat imbalan dan perlakuan yang adil dan layak dalam hubungan kerja.

Namun ternyata ketidakadilan dalam hubungan kerja antara pekerja dengan pengusaha. Marx sebagai orang yang pertama kali melakukan pembedahan terhadap ini berujar bahwa yang dituju kapital bukanlah membantu memenuhi kebutuhan tertentu, tetapi menciptakan laba ${ }^{4}$. Untuk menemukan ketidakadilan tersebut dapat dilakukan dalam paradigma Marx, yakni dengan perspktif hubungan produksi, yang dalam hal ini akan selalu bersinggungan dengan komoditi, nilai, upah, dan laba. Komoditi adalah hasil kerja manusia yang sengaja diproduksi untuk dipertukarkan melalui mekanisme pasar ${ }^{5}$. Suatu komoditi memiliki nilai dalam bentuk harga yang terbentuk melalui 3 faktor yakni proses permintaan dan penawaran di pasar, nilai dan komoditi itu sendiri (nilai dari modal berupa bahan baku), dan nilai tenaga kerja. Karena persoalan disini menyangkut hubungan kerja, maka akan dibahas lebih dalam mengenai nilai tenaga kerja.

\section{B. Nilai Tenaga Kerja}

Nilai tenaga kerja ialah nilai komoditi sarana hidup sehari-hari yang dibutuhkan pekerja dan keluarganya dalam konteks sosial-historis-ekonomis tertentu ${ }^{6}$. Sebagai contoh dapat diilustrasikan sebagai berikut : Diketahui dalam hidup satu hari seorang pekerja pabrik pembuat sepeda perlu biaya 15.000 rupiah. Si pekerja membutuhkan kerja sebanyak 4 jam sehari untuk dapat memperoleh 15.000 rupiah tersebut. 4 jam tersebut disebut juga "waktu kerja-perlu" yang setara dengan nilai tenaga kerjanya. Dengan kata lain 15.000 rupiah merupakan nilai tenaga kerja atau disebut juga "nilai perlu" bagi pekerja tersebut jika dituangkan dalam harga ${ }^{7}$. Namun pengusaha akan menjadi rahib apabila membiarkan berhenti bekerja ketika baru menghasilkan nilai yang setara dengan tenaga kerjanya ${ }^{8}$. 
Di Indonesia menurut pasal 77 ayat (2) Undang-Undang No 13 Tahun 2003 dengan peraturan 8 jam sehari dalam 5 hari, maka si pekerja pabrik pembuat sepeda tadi harus bekerja lagi di 4 jam sesudahnya. 4 jam sesudahnya setelah waktu kerja perlu terlampaui disebut "waktu kerja lebih" atau rentang waktu kerja yang diperpanjang rentangnya pekerja menghasilkan nilai yang melebihi nilai tenaga kerjanya atau yang disebut juga "nilai lebih". Nilai lebih inilah yang menjadi sumber laba bagi kapitalis ${ }^{9}$. Hal ini dikarenakan bahwa si pekerja pabrik sepeda tadi mendapat 15.000 rupiah sebagai nilai perlu di 4 jam pertama atau di waktu kerja perlu, sedangkan untuk di 4 jam sesudahnya atau di waktu kerja lebihnya ia tidak mendapat nilai perlu atau dengan kata lain tidak mendapat 15.000 rupiah lagi. Mengapa demikian ? Karena hubungan kerja diantara pekerja dan pengusaha berlandaskan pengupahan yang membuat si pekerja tadi hanya mendapat 15.000 rupiah per hari.

Yang tadi hanya secara dasar saja, karena sepanjang sejarah kapitalisme hingga hari ini, ada 2 jalan untuk meningkatkan nilai-lebih, yaitu memperpanjang rentang waktu kerja lebih dan memperpendek rentang waktu kerja perlu. Selain itu seiring perkembangan teknologi, juga dapat dengan cara peningkatan manajemen, teknik, motivasi kerja, dan segala hal lain yang dapat menyusutkan nilai kerja perlu. Oleh Marx, nilai lebih yang dihasilkan dengan penyusutan waktu dan nilai kerja perlu ini disebut "nilai lebih relatif"10.

Disinilah letak benih ketidakadilan yang dimaksud. Berdasar pada keadilan distributif $^{11}$, jasa pekerja di waktu kerja perlu tadi ternyata tidak dihargai.dengan sistem upah, nilai kerja lebih yang dihasilkan tidak dibagi ke pekerja, melainkan hanya kepada pengusaha. Ketidakadilan yang terjadi makin ditambah pula jika dikaitkan dengan perspektif keadilan komutatif dan keadilan konstitusional. Keadilan komutatif mengisyaratkan bahwa negara melalui pemerintah harus memberi hak-hak yang sama pada warganya, sehingga jika pemerintah memberlakukan sistem upah dengan resiko yang telah diulas tadi maka pemerintah tidaklah memiliki usaha untuk mewujudkan komutatif. Juga jika pemerintah memberlakukan sistem upah, maka secara keadilan konstitusional ${ }^{12}$ hal ini akan diduga bertentangan dengan pasal 28D ayat (2) UUD 1945 sebagai the supreme law of the land. Padahal dapat diingat bahwa pasal terse\$but ialah mengatur tentang hak azasi manusia, sehingga jika pasal tersebut dilanggar maka pemerintah bisa dikatakan menerapkan kebijakan yang tidak humanis. Dan ternyata, Undang-Undang No 13 tahun 2013 tentang Ketenagakerjaan memberlakukan sistem upah dalam hubungan kerja di Indonesia.

Ketika ingin memperbaiki kondisi masyarakat pekerja, maka perbaikilah masalah upah. Adapun sistem upah yang telah menunjukan nasibnya yang makin krisis harus diakhiri dan diganti dengan sistem baru. 


\section{METODOLOGI}

Jenis penelitian yang dilakukan oleh penulis adalah penelitian kualitatif. Metode kualitatif dianggap suatu cara untuk menganalisis realitas sosial secara mendalam. Maka penelitian tentang bagaimana politik, ideologi, analisa kebijakan serta cara media mengemas berita, banyak dilakukan menggunakan metode kualitatif.

Penelitian kualitatif bertujuan untuk mendapatkan pemahaman yang sifatnya umum terhadap kenyataan sosial dari perspektif partisipan. Pemahaman tersebut tidak ditentukan terlebih dahulu, akan tetapi diperboleh setelah melakukan analisis terhadap kenyataan sosial yang menjadi fokus penelitian, dan kemudian ditarik suatu kesimpulan berupa pemahaman umum tentang kenyataan-kenyataan tersebut.

Studi kepustakaan adalah teknik pengumpulan data dengan mengadakan study penelaahan terhadap buku-buku, literatur-literatur, catatan-catatan, dan laporan-laporan yang ada hubungannya dengan masalah yang dipecahkan.

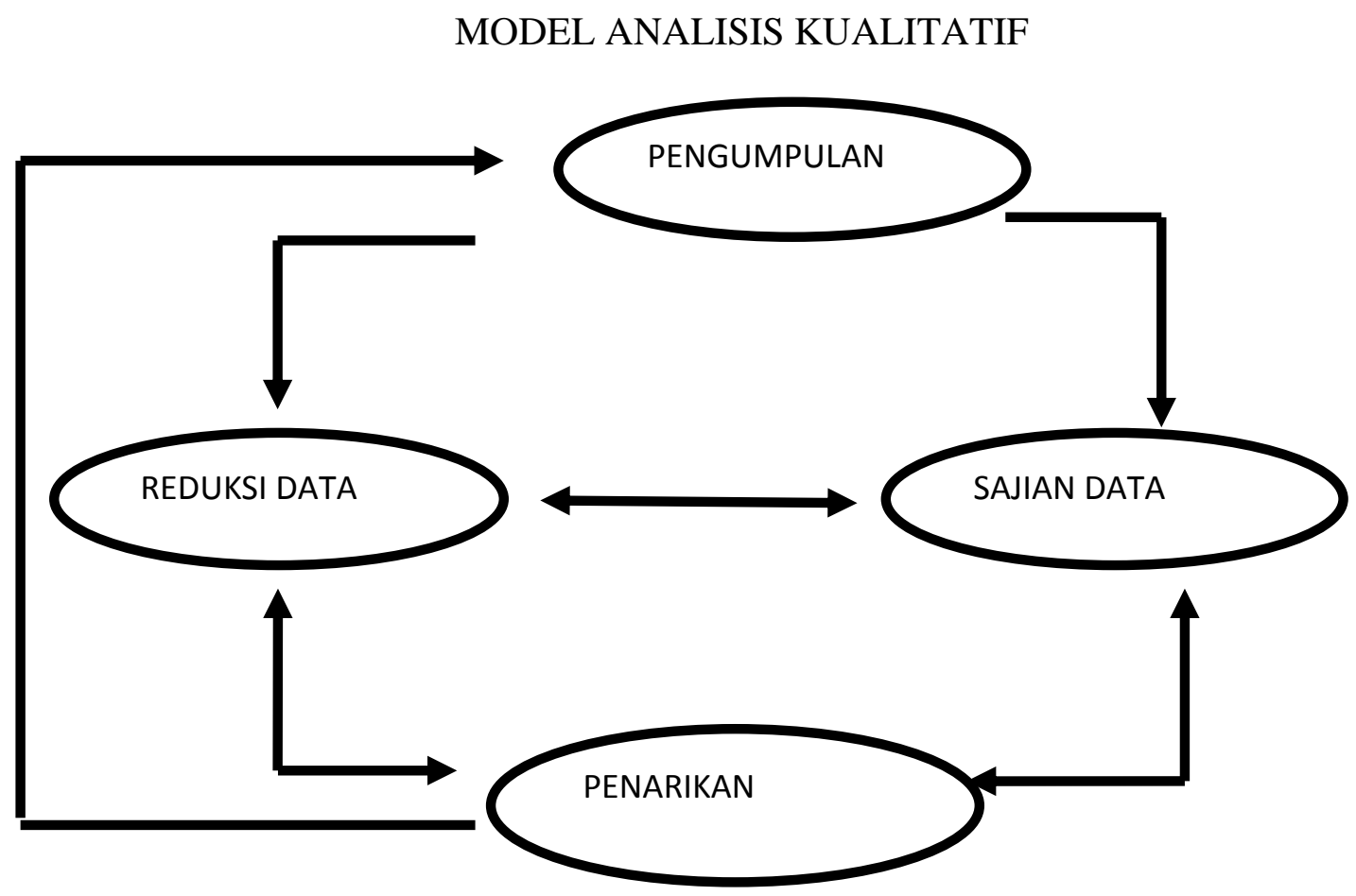

Gambar Model Analisis Interaktif ${ }^{13}$

${ }^{13}$.Miles dan Huberman.1992.Analisa Data Kualitatif.UI Press, Jakarta Hal : 20 


\section{PEMBAHASAN}

A.

Upah Bagi

Hasil

Bagi hasil atau profit sharing, biasa dilakukan pengusaha sebagai solusi alternatif atas krisis sistem upah serta sebagai tambahan penghasilan di luar upah yang secara periodik diterima oleh pekerja ${ }^{14}$. Secara garis besar, konsep Profit sharing membagi sebagian keuntungan perusahaan kepada pekerja yang proporsinya berdasarkan perjanjian antara pengusaha/pemberi kerja dengan pekerja. Dalam perjanjian bagi hasil, yang disepakati adalah proporsi pembagian hasil dalam ukuran presentase atas kemungkinan hasil produktifitas nyata. Proporsi yang muncul berdasarkan perjanjian itu di pengaruhi oleh tiga faktor, yang pertama adalah kontribusi para pihak dalam bekerjasama menghasilkan produk (share and partnership), yang kedua prospek perolehan keuntungan (expected return), dan yang ketiga adalah tingkat resiko yang mungkin terjadi ( expected risk) ${ }^{15}$. Namun profit sharing yanga da belumlah dilakukan secara nasional, hanya pada perusahaan tertentu saja karena tidak ada dasar hukum yang mengatur regulasi secara nasional. Contoh profit sharing yang sukses diterapkan bisa dilihat pada perusahaan Ford ${ }^{16}$. Ford menakjubkan dunia pada 1914 dengan menawarkan upah 5 USD perhari, upah yang dua kali lipat lebih besar dari upah kebanyakan. Dengan kurs tahun 2008, nilai ini setara dengan 106 USD perhari. Sistem ini terlihat menggembirakan dan menguntungkan, konstan dengan produktifitas karyawan, dan menurunkan biaya pelatihan.

Untuk mengantisipasi sistem upah, profit sharing adalah strategi termudah yang adapat diterapkan. Proporsi profit sharing bisa 50\% pekerja 50\% pengusaha, ataupun $60 \%$ pekerja dan $40 \%$ pengusaha, dan sebagainya. Dalam perjanjian bagi hasil, yang disepakati adalah proporsi pembagian hasil dalam ukuran persentase atas kemungkinan hasil produktifitas nyata. Proporsi yang muncul berdasarkan perjanjian itu dipengaruhi oleh tiga faktor, yang pertama adalah kontribusi para pihak dalam menghasilkan produk (share and partnership), yang kedua prospek perolehan keuntungan (expected return), dan yang ketiga adalah tingkat resiko yang mungkin terjadi (expected risk) ${ }^{17}$. Sehingga nantinya baik itu laba maupun rugi, akan dibagi ke pihak pekerja maupun pengusaha. Karena kedua belah pihak pastinya tidak mau sama-sama merugi, maka mereka harus kooperatif memajukan perusahaan.

Konsep semacam ini sebenarnya telah bersinggungan dengan konsep ekonomi kerakyatan yang pada awal kemerdekaan Indonesia telah dicanangan oleh para pendiri bangsa. Sumber dari sistem ini adalah pasal 33 UUD 1945. Dalam konsep ini, masyarakat memiliki kedudukan penting dalam kegiatan perekonomian. 
Kedudukan anggota masyarakat sebagai subyek perekonomian itu memiliki konsekuensi yang sangat luas terhadap penyelenggara sistem ekonomi kerakyatan. Sebagai subyek perekonomian Indonesia, maka setiap anggota masyarakat harus turut memiliki alatalat produksi (co-ownership), turut mengambil keputusan-keputusan ekonomi (codetermination), dan turut pula menanggung segala akibat dari pelaksanaan keputusankeputusan ekonomi tersebut (co-responsibility). Konsep triple co tidak hanya menghadirkan subsistensi dan mekanisme yang partisipatoris, tetapi sekaligus emansipatoris. ${ }^{18}$

Menteri Tenaga Kerja dan Transmigrasi Muhamaimin Iskandar menyebut metode penerapan bagi hasil produktivitas atau "productivity gain sharing" dapat menjadi salah satu alternatif sistem pengupahan. Model pengupahan dengan mempertimbangkan konsep productivity gain sharing ini mampu membangun kemitraan antara pengusaha dan pekerja dalam menentukan skala upah secara bipartit. Dengan menggunakan metode ini, setiap pertumbuhan produktiviitas yang dicapai oleh perusahaan bisa memberikan sumbangannya pada upah buruh. Dengan model ini, maka akan timbul motivasi tenaga kerja untuk meningkatakn kinerja secara bertanggung jawab dalam rangka mendongkrak perumbuhan nilai tambah perusahaan. Dengan pertumbuhan nilai tambah perusahaan tersebut, maka akan meningkatkan pendapatan tenaga kerja itu sendiri. Penerapan bagi hasil produktivitas, kata dia, sejalan dengan amanat Undang-Undang Nomor 13 Tahun 2003 tentang Ketenagakerjaan, khususnya pada pasal 92 ayat 2, yang menyebutkan bahwa pengusaha menetapkan skala upah berdasarkan kemampuan perusahaan dan produktivitas. Begitu juga dalam Inpres Nomor 9 Tahun 2013, Presiden juga telah mengintruksikan untuk merumuskan secara komperhensif sistem pengupahan nasional yang mampu mengakomodasi kepentingan baik pengusaha maupun tenaga kerja. ${ }^{19}$

Namun profit sharing bukan solusi mutakhir hubungan kerja karena profit sharing sendiri masih mencirikan adanya kapitalisme, yang disebut Henry Ford sebagai "Kapitalisme Kesejahteraan" 20 . Hubungan kerja yang sub-ordinan antara pemberi kerja masih ada dalam sistem ini. Ada pun system hanya efektif dan efisien dilakukan oleh perusahaan kecil, kurang lebih pekerjanya100 orang.

\footnotetext{
${ }^{18}$ Revrisond Baswir, Manifesto Ekonomi Kerakyatan, Pustaka Pelajar, Yogyakarta,2009,hal 28

${ }^{19} \mathrm{http}: / / \mathrm{www}$.antaranews.com/berita/402925/menakertrans-usulkan-pengupahan-bagi-hasil, diakses pada 3 Juli 2014

${ }^{20} \mathrm{http}$ ://id.wikipedia.org/wiki/Henry_Ford. Diakses pada 13 Maret 2013 pukul 12:51
} 
Sistem ini kurang cocok pada perusahaan yang pekerjanya memiliki tingkat kesadaran yang lebih maju. Dlam tahap tingkat kesadaran pekerja yang lebih maju, ruang-ruang demokrasi sangat dibutuhkan dalam pengambilan kebijakan kerja. Sedangkan profit sharing tidak memiliki mekanisme membuka ruang-ruang demokratis, dalam artian hanya penyumbang saham terbesarlah (One share One vote) yang menentukan kebijakan kerja sekalipun pembagian hasil sudah diatur oleh bersama.

B. Swakelola Manajemen

Dalam tahapan kesadaran pekerja yang lebih maju ada sebuah alternatif selanjutnya yang dimaksud dapat dijumpai melalui bentuk self management atau swakelola pekerja ${ }^{21}$. Swakelola pekerja atau manajemen hirarkis yang baku. Sebagai gantinya, tempat kerja tersebut dikelola secara demokratis oleh para pekerja. Dengan demokrasi, para pekerja sendiri yang memutuskan apa yang mereka lakukan sebagai sebuah kelompok. Tidak ada seorang pun dalam badan usaha ynag dikelola secara mandiri, memiliki kontrol atas pekerja lainnya dalam menentukan setiap keputusan ada ditangan para pekerja secara setara. Dengan mengacu sistem ekonomi, swakelola berarti pola manajemen langsung oleh prdusen, mulai dari produksi, distribusi hingga komunikasi langsung ke komunitas atau masyarakat.

Secara empirik swakelola bukanlah ide abstrak atau rencana besar utopis yang harus diinjeksikan ke dalam pikiran "massa". Dalam sejarah swakelola berulang hadir di Rusia 1905 dan 1917, di Spanyol 1936-1937, di Hungaria 1956, Aljazair 1960, di Chili 1972 hingga Argentina $2001^{22}$. Bentuk organisasi sistem swakelola yang sering dibangun adalah Dewan Pekerja.

Tahun 2001, Argentina guncang. Krisis ekonomi yang diikuti dengan krisis politik menyebabkan situasi menjadi tidak terkendali. Hal tersebut adalah dampak dari diterapkannya ekonomi neoliberalisme yang memaksa seluruh kelas pekerja semakin miskin dan menderita. Hasilnya, kemiskinan yang luar biasa, sekitar 50\% pengangguran dan kelaparan. Puncaknya saat ribuan pabrik dan perusahaan ditinggal tutup oleh pemiliknya atas alasan stabilitas. Akibatnya jutaan orang kehilangan pekerjaan. Bangkrutnya perekonomian Argentina tidak serta merta membangkrutkan kesadaran kelas pekerja di negara itu. Kelas pekerja Argentina yang sejak beberapa tahun sebelumnya berjuang, terus bangkit dan mengancam secara serius kekuasaan negara. Bayangkan, lima pemerintahan dijungkalakan hanya dalam tiga minggu! Inilah yang kemudian menjadi momentum penyebaran perlawanan meluas ke seantero negeri. Pemberontakan tersebut merupakan reaksi dari 

krisis ekonomi dimana bank-bank, monopoli kapitalis, IMF dan intervensi AS serta politisi Argentina telah menjadi penyulutnya. Pemberontakan kelas pekerja Argentina terus berlanjut namun justru mengambil bentuk berbeda. Tidak seperti kebiasaan menekan pemerintah dan kaum kapitalis untuk memenuhi tuntutan mereka, kelas pekerja justru bergerak lebih jauh melampaui metode dan taktik moderat tersebut. Mereka menduduki dan mengambilalih perusahaan dan pabrik. Dan melampauinya sekali lagi : mereka mengoperasikannya tanpa eksistensi majikan, manajemen birokratis, atas campur tangan negara dan pemerintah dalamurusan produksi. Sebuah bentuk swakelola dimana kontrol atas proses produksi dan manajemen perusahaan sepenuhnya berada ditangan pekerja. ${ }^{23}$

Pabrik pertama yang diambil alih adalah YaguanE, sebuah perusahaan penyimpanan dan pendinginan (cold stroage) di tahun 1996, dan menyusul IMPA di tahun 1998. Berikutnya di tahun 2000, 90 orang pekerja logam dipecat dari perusahaan tempatnya bekerja, mereka lalu membangun UniUn y Fuerza (Unity ad Strength) atau Persatuan dan Kekuatan, sebuah komite pekerja yang berupaya membangun unit produksi mandiri. ${ }^{24}$

Gaji yang diberikan sma besarnya untuk semua posisi. Dalam pengalaman manajemen non hirarkis tersebut, perusahaan telah melakukan efisiensi dengan menekan pospos pembiayaan yang tidak perlu. Para pekerja mengaku sangat puas dengan model swakelola. Di era sebelumnya, perusahaan mengalokasikan $65-70 \%$ anggaran untuk gaji majikan dan manajemen. Dengan model swakelola, kesejahteraan pekerja lebih merata. ${ }^{25}$

Koordinasi kerja harian dilakukan lewat pertemuan Dewan Pekerja di tiap divisi atau unit kerja. Fungsi pertemuan tersebut membicarakan maslah kerja dan mengambil keputusan harian. Taiap divisi atau unit kerja mengirimkan delegasi dengan mandat khusus ke sebuah komite kerja untuk mengkoordinasikan aktivitas mereka dengan unit kerja lainnya. Delegasi disini bukan berarti manager profesional tetapi pekerja biasa yang didelegasikan dari unit kerjanya untuk melaporkan aktivitas kepada Dewan Kerja. Setelah pertemuan Dewan Pekerja usai, delegasi pun kembali beraktifitas kembali seperti pekerja lainnya.

Delegasi dapat di-recall atau diganti kapan saja bergantung kepada para pekerja. Sebuah komite kerja bukanlah bentuk manajemen sebagaimana yang dimaksud peusahaanperusahaan kapitalis. Merea tidak membuat keputusan kepada pekerja lainnya melainkan sebagai komunikasi antar unit-unit kerja lainnya. Komite bukan pula sebuah badan permanen yang anggota pekerjanya hanya itu itu saja, melainkan setiap pekerja lain dapat menjalankan peran tersebut. 
Esensi dari sistem kerja swakelola bertujuan dalam penghapusan kerja upahan dan komoditi ekonomi. Sebuah model manajemen langsung swakelola diterapkan dengan sistem demokrasi langsung tanpa kecuali dimana pendelegasin berlangsung secara ketat untuk menghindari sentralisasi kekuasaan dan manipulasi ${ }^{26}$. Perlu dipahami bahwa keberhasilan swakelola terletak pada kesadaran pekerja ditingkat individu, akan hasrat yang mendalam bagi penciptaan yang bebas, kreatif dan menyenangkaan dibawah kontrol mereka sendiri.

Namun bukan berarti swakelola lebih baik dari bagi hasil. Semua tergantung pada tingkat kesadaran pekerjanya. Sehingga kedua gagasan ini dipersilahkan menjadi pilihan masyarakat, tergantung dari kondisi pekerja di masing-masing wilayah kerja. Namun pada intinya, sistem upah tetap harus diganti dengan baik sistem bagi hasil maupun swakelola.

Karena bagaimanapun, konsep ini berawal dari pemahaman bahwa buruh berada dalam posisi yang dilematis, disatu sisi buruh adalah kelas tertindas tetapi disatu sisi buruh adalah bagian terpenting dari proses produksi sehingga kesejahterannya harus diperjuangkan.

Perjuangan upah biasanya merupakan reaksi atas perubahan-perubahan sebelumnya dalam kapitalisme. Ada setidaknya empat situasi ${ }^{27}$ yang mendorong perjuangan upah, baik itu perjuangan untuk menaikkan upah ataupun menahan penurunan upah. Situasi yang pertama adalah jika terdapat perubahan produktivitas kerja. Kalau produktivitas turun, sehingga diperlukan kuantitas kerja yang lebih besar untuk meproduksi barang-barang kebutuhan hidup, maka nilai tenaga-kerja akan anaik dan keuntungan akan turun. Jika upah tidak naik, atau naik tetapi tidak sebanding dengan naiknya nilai barang-barang kebutuhan hidup, maka upah aka berada dibawah nilai tenaga-kerja dan standar kehidupan buruh akan turun. Kalau terjadi perjuangan upah dalam situasi ini, maka perjuangan itu adalah untuk menaikkan upah agar sesuai dengan nilai tenaga-kerja.

Sebaliknya, jika produktivitas meningkat, maka nilai barang-barang kebutuhan hidup dan tenaga-kerja akan turun, sementara keuntungan akan naik. Dalam situasi ini, stanar kehidupan buruh akan tetap sama, tetapi upah relatif-upah berbanding keuntungan-dan posisi sosial relatif buruh akan turun. Kalau terjadi perjuangan upah dalam situasi ini, maka hal itu adalah karena buruh mencoba mendapatkan bagian dari peningkatan produktivitas kerjanay dan untuk mempertahankan posisi sosial relatifnya.

\footnotetext{
${ }^{26}$ http://jurnal kontinun/read/news/2008/11/swakelola sebagai alternatif radikal, diakses pada 12 Maret pukul 01:26

${ }^{27}$ Mohamad Zaki Hussein, Perjuangan Upah dan Kapitalisme, diakses pada www.indoprogress.com 3 Juli 2014
} 
Situasi yang kedua adalah jika nilai uang berubah, sementara nilai barang-barang kebutuhan hidup dan tenaga-kerja tidak berubah. Misalnya, ekspresi moneter dari 6 jam kerja adalah Rp. 7000;. Lalu, niali mata uang turun sebesar 50 persen. Dalam hal ini, Rp. 7000; tidak lagi sama dengan 6 jam kerja, tetapi menjadi sama dengan 3 jam kerja. Kalau upah tidak naik ketika nilai mata uang turun, maka upah akan mengekspresikan nilai tenaga-kerja yang lebih sedikit adri sebelumnya, sehingga standar kehidupan buruh akan turun. Hal ini juga berlaku jika upah naik tetapi tidak sebanding dengan turunnya nilai uang.

Situasi yang ketiga adalah jika terjadi perpanjangan jam kerja. Hal ini mungkin jarang terjadi di masa sekarang. Tetapi, selama perang anti-Jacobin di Inggris, jam kerja pernah diperpanjang dari 10 jam menjadi 12, 14, dan bahkan 18 jam. Kapital, jika tidak ditahan, memiliki kecenerungan untuk memperpanjang jam kerja, karena dengannya, nilai surplus atau keuntungan akan bertambah. Selain itu, kapital juga bisa meningkatkan intentitas kerja dengan mempercepat operasi mesin, dan sebagainya, sehingga dengan waktu kerja yang sama, seotang buruh bisa mengeluarkan tenaga lebih banyak dari sebelumnya. Jika hal ini terjadi, perjuangan untuk menaikkan upah sebenarnya merupakan upaya buruh untuk mengimbangi perpanjangan jam kerja atau intentitas kerja dan menahan kemerosotan hidupnya.

Situasi yang keempat terkait dengan krisis. Kapiatlisme bergerak melaui siklus pertumbuhan, krisis dan stagnasi. Harga pasar komoditi dan tingkat keuntungan sesuai harga pasar juga mengikuti siklus ini, kadang di atas, kadang di bawah rata-rata. Pada fase krisis stagnasi, pekkerja akan mengalami penurunan upah. Perjuangan di fase ini ditujukan agar buruh tidak ditipu kapitalis \$dan penurunan upah sesuai dengan yang diperlukan. Pada fase pertumbuhan, dimana para kapitalis mendapatkan keuntungan ekstra, buruh pun harus berjuang melawan kapitalis agar upah tidak di bawah rata-rata dan sesuai dengan nilai tenaga-kerjanya.

\section{DAFTAR PUSTAKA}

\section{Peraturan Perundang-Undangan}

Undang-Undang Dasar Negara Republik Indonesia 1945

Undang-Undang Nomor 13 Tahun 2003

\section{Literatur}

Apeldoom, Van. Pengantar Ilmu Hukum: Pradnya Paramita 1986

Erman, Erwiza. Kesenjangan Buruh Majikan :Pengusaha, Kecil dan Penguasa Industri Timah Belitung, 1852-1940. Jakaerta : Pustaka Sinar Harapan, 1994 
Fakih, Mansour. Runtuhnya Teori Pembangunan dan Globalisasi. Yogyakarta : INSISTPress, 2009

Lafargue, Paul. Hak Untuk Malas. Yogyakarta dan Bandung : Jalasutra, 2008

Lexy J. Moleong, Metode Penelitian Kualitatif, Remaja Rosdakarya, Bandung, 2006

Marx, Karl. Karl Marx and Fredrick Engels Selected Works. Moskow : Foreign Languangers Publishing House, 1962

Marx, Carl. Capital : a Critique of Political Economy. London : Penguin Books, 1992

Moh Nazir, 2011, Metode Penelitian,Ghalia Indonesia, Jakarta

Mulyanto, Dede. Antropologi Marx : Karl Marx Tentang Masyarakat dan Kebudayaan, Bandung : Ultimus, 2011

Mulyanto, Dede. Genealogi Kapitalisme : Antropologi dan Ekonomi Politik Pranata Eksploitasi Kapitalistik. Yogyakarta : Resist Book, 2012

Setiawan, Bonnie. WTO dan Perdagangan Abad 21, Yogyakarta : Resist Boo, 2013

Silaban, Rekson. Reposisi Gerakan Kamu Buruh. Jakarta : Pustaka Sinar Harapan, 2009

Tanya, Bernard L. Politik Hukum, Agenda Kepentingan Bersama. Yogyakarta : Genta Publishing, 2011

Triton. Manajemen Sumber Daya Manusia. Yogyakarta : ORYZA, 2010

\section{JURNAL}

Muchlis Yahya dan Edy Yusuf Agunggunanto. Teori Bagi Hasil (Profit and Loss sharing)

dalam perbankan syariah dan ekonomi syariah, Jurnal Dinamika Ekonomi Pembangunan,

Volume I, 2011

Haryo Kuncoro. Upah Sistem Bagi Hasil dan Penyerapan Tenaga Kerja, Jurnal Ekonomi

Pembangunan Volume 7, 2002

\section{Internet}

Wikipedia, Henry Ford, dlam http://id.wikipedia.org/wiki/Henry_Ford

Jurnal Kontinum, Swakelola Sebagai Alternatif Radikal, dalam http : //jurnal kontinum/read/news/2008/11/Swakelola sebagai alternatif radikal

Jurnal Kontinum, Potret Swakelola di Argentina, dalam http: //jurnal kontinum/read/news/2008/11/Potret Swakelola di Argentina

Mohamad Zaki Hussein, Perjuangan Upah dan Kapitalisme, diakses pada www.indoprogress.com

Oktomagazine, Membangun Perusahaan Dengan Sistem Bagi Hasil, dalam http://m.oktomagazine.com/oktolifestyle/wirausaha/3320/membangun.perusahaan.dengan.sist $\underline{\text { em.ba }}$ 
Tempo, Buruh Minta Outsourcing Dihapus, http://www.tempo.co/read/news/2011/05 02/083331436/Buruh-Minta-Outsourcing-Dihapus 